\title{
When to suspect a thymoma: clinical point of view
}

\author{
Fabrizio Minervini ${ }^{1}$, Gregor J. Kocher ${ }^{2}$ \\ ${ }^{1}$ Department of Thoracic Surgery, Kantonsspital Luzern, Lucerne, Switzerland; ${ }^{2}$ Division of General Thoracic Surgery, Inselspital, Bern University \\ Hospital, University of Bern, Bern, Switzerland \\ Contributions: (I) Conception and design: F Minervini; (II) Administrative support: None; (III) Provision of study materials or patients: All authors; (IV) \\ Collection and assembly of data: All authors; (V) Data analysis and interpretation: None; (VI) Manuscript writing: All authors; (VII) Final approval of \\ manuscript: All authors. \\ Correspondence to: Fabrizio Minervini, MD, PhD. Department of Thoracic Surgery, Kantonsspital Luzern, Spitalstrasse, 6000 Lucerne, Switzerland. \\ Email: fabriziominervini@hotmail.com.
}

\begin{abstract}
The thymus plays a crucial role in the development of immune system, regulating the maturation, selection and migration of T lymphocytes. Alterations in lymphatic content and structure of the thymus are observed in many autoimmune diseases. Moreover, changes of the epithelial component may cause the development of thymic tumours. Thymoma is a rare epithelial tumor of the anterior mediastinal compartment with a wide spectrum of clinical presentations. The causes of thymoma are still unknown and several hypotheses have been formulated. Thymomas show a variable course causing, frequently, a prolonged clinical history. The presence of metastasis at the time of diagnosis is very uncommon. Even if about $30 \%$ of the patients with thymoma are asymptomatic, they may have local symptoms (such as cough, pain, hoarseness, and dyspnea) or paraneoplastic disorders. The role of immune system in the pathogenesis of these tumors and related paraneoplastic syndromes is not completely clear. A clinical diagnosis, especially if the first manifestation is a thymoma-associated paraneoplastic disease, is not always easy and should be supported by an appropriate imaging in order to guide the proper management for each patient. In this article, we would like to give an overview of the local and systemic clinical manifestations, which can be found in patients affected by thymoma.
\end{abstract}

Keywords: Thymoma; myasthenia gravis; thymic neoplasm

Submitted Dec 18, 2019. Accepted for publication May 27, 2020.

doi: $10.21037 /$ jtd-2019-thym-05

View this article at: http://dx.doi.org/10.21037/jtd-2019-thym-05

\section{Introduction}

Even though rare, thymomas are the most common neoplasms arising from the thymic epithelium of the anterior mediastinum. With an incidence of 0.13 cases per 100,000 persons/year in the USA, they can occur in patients of any age but are very rare in the first 2 decades of life (1). The ratio of men to women in the published literature is roughly equal. Given the rarity of thymomas, the knowledge about the etiology is very limited. A causal relationship between tobacco, alcohol or environmental factors and an increased incidence of thymoma has never been demonstrated.

Histologically thymoma arises from thymic epithelial cells but contains a variable number of lymphocytes, which are not neoplastic.

Subtyping and classifying thymomas has represented a big challenge and indeed several pathologic, clinical and surgical classifications have been developed and published over the years. In 1961, Bernatz and colleagues classified thymoma based on the predominant lymphocytes and epithelial component (2).

Fifteen years later, Rosai and Levine (3) focused their attention on the presence or absence of invasiveness describing thymoma as (I) benign encapsulated thymoma, (II) type 1 malignant thymoma (invasive), and (III) type 2 malignant thymoma (thymic carcinomas).

In 1985, Marino and Müller-Hermelink reported a new 


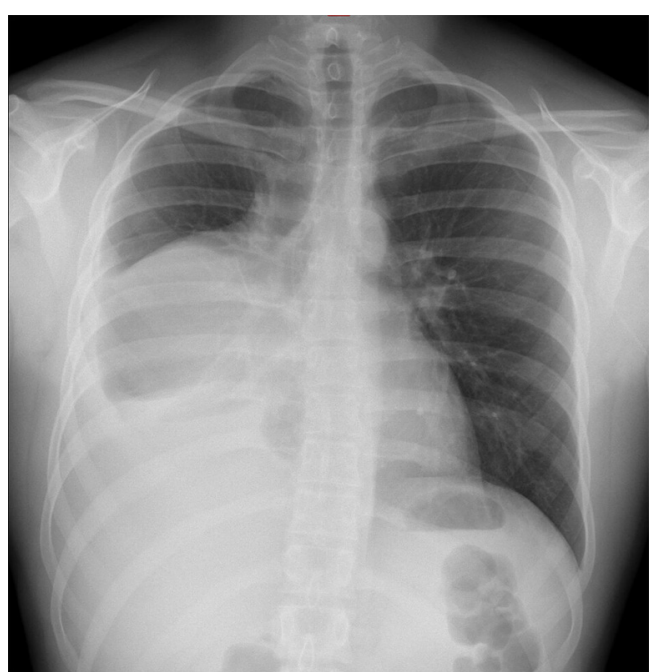

Figure 1 Chest X-ray showing a mediastinal mass protruding to the right hemithorax.

classification according to the assumed localization of the malignant thymus cells including five subtypes: medullary, mixed, predominantly cortical, cortical thymomas, and welldifferentiated thymic carcinomas (4).

Nowadays, the WHO histologic classification along with Masaoka are the most broadly used classification systems for thymic epithelial tumors, providing a useful guidance for surgeons, oncologists and radiation oncologists in clinical decision-making (5-7).

\section{Clinical features of thymoma}

Clinical presentation of thymomas can vary from an incidental finding on chest radiography (Figure 1) or computed tomography (CT) scan (Figure 2), to symptoms deriving from mass effect in the mediastinum or from a systemic syndrome. About $30 \%$ of thymoma patients are asymptomatic and the diagnosis is made incidentally; maybe this percentage will continue to rise due to the increasing and widespread use of CT scans, also in the setting of lung cancer screening.

Up to $80 \%$ of thymomas are visible on chest radiography, although without any specific signs. Usually they present like an ovoid or lobulated, smooth, well-marginated mediastinal tumor, abutting unilaterally (rarely this mass may protrude bilaterally). In the lateral view such masses are often easily visible as an abnormal radiopacity in the retrosternal space (8).

The typical CT features of thymoma (well defined

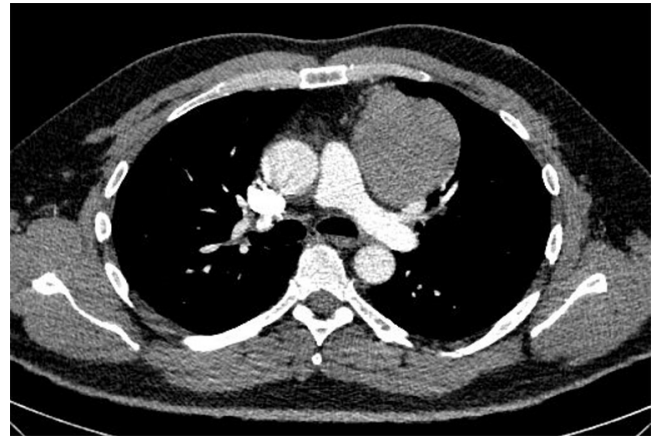

Figure 2 Chest CT showing a mediastinal mass. CT, computed tomography.

and distinct from the surrounding mediastinal fat, round or lobulated, homogenous) are highly evocative of the diagnosis. Unlike other mediastinal tumors, thymomas are usually not associated with metastatic lymphadenopathy or with lung metastases. The use of intravenous contrast is not mandatory per se in order to characterize the thymic mass but it may certainly help in evaluating the invasiveness of the tumor in the preoperative staging and, therefore, therapeutic decision-making.

The tumor is usually located ventral to the pericardium, aorta, pulmonary artery, or superior vena cava, despite thymomas have been reported in locations everywhere between the lower neck and the cardiophrenic space (8).

The local tumor growth could trigger several symptoms due to compression and/or invasion of adjacent structures. However, even patients with invasive lesions tend to show a prolonged clinical course. The most common symptoms, although nonspecific, are chest discomfort/pain, cough and dyspnea. If thymoma has a more aggressive behavior growing abnormally, some unusual manifestations, such as superior vena cava syndrome and phrenic nerve paralysis, may be present. Stridor and dysphagia can be late signs, caused by compression of the trachea and/or esophagus.

The presence of pleural or pericardial effusion is very unusual and may suggest an advanced stage of the disease.

Very rare, with few cases published in the literature, is the spontaneous rupture of thymoma as onset manifestation of the tumor (9-11)

\section{Myasthenia gravis}

Thirty-five percent of patients with thymoma have myasthenia gravis (MG; from Greek: myos = muscle, asthenos = weakness, and Latin: gravis =severe), a complex autoimmune disorders 
Table 1 Clinical subgroups of MG

\begin{tabular}{|c|c|c|c|c|}
\hline MG subgroups & Clinical features & Genetic variant associated & Antigen & Thymus pathology \\
\hline Late onset MG (LOMG) & $\begin{array}{l}\text { Age of presentation }>50 \text { years; } \\
\text { rate female/male } 1 / 1.5\end{array}$ & HLA-A3, B7, DRw2 & $\mathrm{AChR}$ & Absence of thymus pathology \\
\hline $\begin{array}{l}\text { Thymoma-associated } \\
\text { MG (TAMG) }\end{array}$ & Paraneoplastic MG & - & $\mathrm{AChR}$ & Thymoma \\
\hline Ocular MG (OMG) & Ocular form & - & $\mathrm{AChR}$ & Variable \\
\hline MuSK MG & $\begin{array}{l}\text { Severe presentation, respiratory + bulbar } \\
\text { muscle weakness; rate female/male } 9 / 1\end{array}$ & HLA-DR14-DQ5 & MuSK & Absence of thymus pathology \\
\hline Lrp4 MG & Mild phenotype; rate female/male $2.5 / 1$ & - & Lrp4 & Variable \\
\hline
\end{tabular}

MG, myasthenia gravis; AChR, acetylcholine receptor; MuSK, muscle specific tyrosine kinase.

characterized by increasing muscle fatigability and weakness which involves skeletal muscles and is caused, in more than $85 \%$ of cases, by circulating antibodies against nicotinic acetylcholine receptors (AChRs) (12).

MG is an uncommon disease with a bimodal agerelated incidence peak (patients between 20-30 years and between $60-80$ years) (13). The specific pathophysiologic mechanisms that lead to the AChRs antibodies production are not fully understood.

The most likely hypothesis is that, in some patients, auto-reactive $\mathrm{T}$ cells can recruit AChR-responsive $\mathrm{B}$ cells, stimulating the production of pathogenic anti AChR antibodies. Consequently, the decreased number of functional AChRs causes a deficit in neuromuscular transmission (14). The reasons of the $\mathrm{T}$ cells deregulation remain unclear, even if Epstein-Barr virus infection has been postulated (15). However, $20 \%$ of patients with MG have no circulating antibodies against AChR but rather present antibodies against muscle specific tyrosine kinase (MuSK), a subclass of immunoglobulin G4.

Up to $50 \%$ of patients with AChR and MuSK negative antibodies present anti-low-density lipoprotein receptorrelated protein 4 (Lrp4) antibodies, an immunoglobulin G1 subclass which inhibits the binding of their target with agrin, a protein which plays a key role in the structure and function of the neuromuscular junction.

The subtypization of the abovementioned antibodies is very important because symptom distribution and response to treatment differ between the various form of MG (Table 1) (14).

The symptomatology of MG consists mainly of voluntary muscles fluctuating weakness (Table 2). In an early phase, patients often complain of ocular muscle weakness with ptosis along with diplopia without deficits of sensorium. Most patients show a progress to generalized weakness during the first 2 years after the diagnosis. Fatigue of the proximal limbs muscles causes difficulties in climbing stairs and holding the arms above the head.

Other potential involved muscles are the bulbar muscles, resulting in dysarthria, dysphagia, difficult mastication, and dyspnea.

Impairment of the facial muscles can produce the so called "hanging jaw sign" (because of the inability to hold the mouth closed) and the "myasthenic snarl" (when patients try to smile).

One of the very typical aspects of this disease is the fluctuation and variability of symptoms within a period of a day (muscle fatigability exacerbates in the evening), months or years. As such, patients can experience periods of remission and periods with severe exacerbations.

The most feared complication of MG is a myasthenic crisis, often triggered by a respiratory infection or surgical procedures. The majority of patients with a myasthenic crisis must be admitted to an intensive care unit where the respiratory failure usually requires ventilatory assistance (non-invasive or with endotracheal intubation). The overall mortality of such a crisis has decreased in the past 50 years from $50 \%$ to $6 \%$.

The diagnosis is nowadays made by detecting the presence of myasthenic antibodies in the serum, by performing electrophysiological tests such as single-fiber 
Table 2 Myasthenia Gravis Foundation of America (MGFA) classification (16)

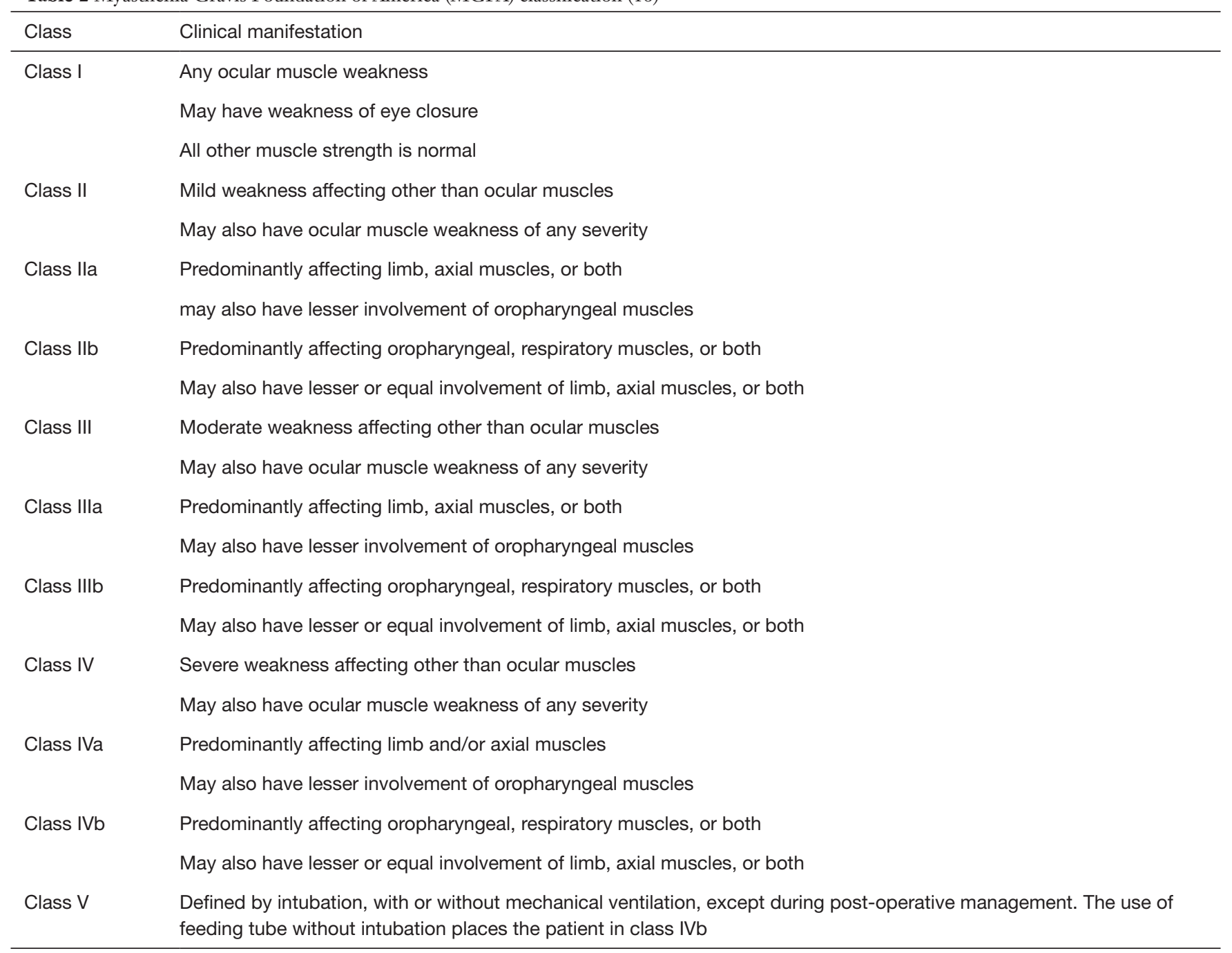

electromyography (SFEMG), and by repetitive nerve stimulation (RNS). Suppression of acetylcholinesterase (AChE) with pyridostigmine or ice pack test, which normally ameliorates the symptoms, have been widely used.

All patients with MG should be screened with a CT scan of the chest searching for possible thymic hyperplasia or tumors. In case of radiologically suspect features, a biopsy should be avoided due to the risk of exacerbating the disease as well as to prevent potential spilling/seeding of tumor cells.

An interdisciplinary discussion amongst neurologist and thoracic surgeon is of the essence when evaluating treatment options (anticholinesterase agents, immunosuppressants, plasmapheresis, immunoglobulin, thymectomy) and their sequence.

\section{Paraneoplastic disorders}

It has been reported that $95 \%$ of thymomas show an absence of autoimmune regulator (AIRE) expression along with reduced major histocompatibility complex (MHC) class II expression, suggesting that dysregulation of $\mathrm{T}$ cell growth is one of the main factors in the pathogenesis of paraneoplastic disorders in thymoma (17).

Besides MG, other syndromes commonly associated with thymoma (2-6\%) are pure red cell aplasia and hypogammaglobulinemia. Patients who present with these paraneoplastic conditions should always undergo a chest 
CT scan to rule out a thymoma as primum movens.

Pure red cell aplasia is a rare condition caused by severe normocytic anemia, reticulocytopenia and absence of erythroblasts in the bone marrow, and can only be found in a small percentage of patients with thymoma. Surgical thymectomy is usually indicated in these patients even if the initial remission rate is only $30 \%$ and an additional treatment with corticosteroids, cyclosporine, or cyclophosphamide is therefore mandatory in most patients.

Hypogammaglobulinemia, also known as Good's syndrome, is a rare combined $\mathrm{T}$ - and $\mathrm{B}$-cell immunodeficiency, which renders patients highly susceptible to bacterial, viral, fungal and opportunistic infections. To date the pathophysiology of the disease is not fully understood but in published case series thymoma was an incidental finding on chest radiograph or CT scan in $10-41 \%$ of patients $(18,19)$.

Another possible rare presentation of thymoma is a type of paraneoplastic syndrome that resembles Graft-versus-host disease (GvHD). This syndrome has also been described as "thymoma associated multiorgan autoimmunity" (TAMA) and involves the skin, liver and intestines $(20,21)$. Typical clinical manifestations of TAMA include confluent keratotic papules, scaly plaques, morbilliform eruptions, erythroderma and mucosal erosions, diarrhea and abnormal liver enzyme levels, especially alkaline phosphatase.

Despite the fact that progress has been made regarding the understanding of thymoma and associated paraneoplastic diseases, the gold standard management of affected patients remains unknown.

\section{Conclusions}

Given the variability of thymoma clinical presentations, a high index of suspicion is required in order to establish the right diagnosis. Understanding the role of the thymus in the pathophysiology of different autoimmune diseases may help in case of uncommon presentation.

\section{Acknowledgments}

Funding: None.

\section{Footnote}

Provenance and Peer Review: This article was commissioned by the Guest Editors (Dragana Jovanovic and Semra Bilaceroglu) for the series "Thymoma" published in fournal of Thoracic Disease. The article was sent for external peer review organized by the Guest Editors and the editorial office.

Conflicts of Interest: Both authors have completed the ICMJE uniform disclosure form (available at http://dx.doi. org/10.21037/jtd-2019-thym-05). The series "Thymoma" was commissioned by the editorial office without any funding or sponsorship. The authors have no other conflicts of interest to declare.

Ethical Statement: The authors are accountable for all aspects of the work in ensuring that questions related to the accuracy or integrity of any part of the work are appropriately investigated and resolved.

Open Access Statement: This is an Open Access article distributed in accordance with the Creative Commons Attribution-NonCommercial-NoDerivs 4.0 International License (CC BY-NC-ND 4.0), which permits the noncommercial replication and distribution of the article with the strict proviso that no changes or edits are made and the original work is properly cited (including links to both the formal publication through the relevant DOI and the license). See: https://creativecommons.org/licenses/by-nc-nd/4.0/.

\section{References}

1. Engels EA. Epidemiology of thymoma and associated malignancies. J Thorac Oncol 2010;5:S260-5.

2. Bernatz PE, Harrison EG, Clagett OT. Thymoma: a clinicopathologic study. J Thorac Cardiovasc Surg 1961;42:424-44.

3. Rosai J, Levine GD. Tumors of the thymus. In: Atlas of Tumor Pathology 2nd series, Fasc 13. Washington, DC: Armed Forces Institute of Pathology, 1976.

4. Marino M, Müller-Hermelink HK. Thymoma and thymic carcinoma. Relation of thymoma epithelial cells to the cortical and medullary differentiation of thymus. Virchows Arch A Pathol Anat Histopathol 1985;407:119-49.

5. Travis WD, Brambilla E, Burke AP, et al. WHO Classification of Tumours of the Lung, Pleura, Thymus and Heart. 4th edition. Lyon: International Agency for Research on Cancer, IARC Press, 2015.

6. Masaoka A, Monden Y, Nakahara K, et al. Follow-up study of thymomas with special reference to their clinical stages. Cancer 1981;48:2485-92.

7. Koga K, Matsuno Y, Noguchi M, et al. A review of 79 thymomas: modification of staging system and reappraisal 
of conventional division into invasive and non-invasive thymoma. Pathol Int 1994;44:359-67.

8. Marom EM. Imaging thymoma. J Thorac Oncol 2010;5:S296-303.

9. Hokka D, Ogawa H, Tane Set al. Ruptured thymoma causing a hemothorax: A case report. Oncol Lett 2015;10:1810-2.

10. Sinyagovskiy P, Abdalla M, Raja A, et al. Spontaneous rupture of thymoma. Respir Med Case Rep 2018;26:56-8.

11. Santoprete S, Ragusa M, Urbani M, et al. Shock induced by spontaneous rupture of a giant thymoma. Ann Thorac Surg 2007;83:1526-8.

12. Meriggioli MN, Sanders DB. Muscle autoantibodies in myasthenia gravis: beyond diagnosis? Expert Rev Clin Immunol 2012;8:427-38.

13. Osserman KE, Genkins G. Studies in myasthenia gravis: review of a twenty-year experience in over 1200 patients. Mt Sinai J Med 1971;38:497-537.

14. Koneczny I, Herbst R. Myasthenia Gravis: Pathogenic Effects of Autoantibodies on Neuromuscular Architecture. Cells 2019;8:671.

15. Cavalcante P, Maggi L, Colleoni L, et al. Inflammation and epstein-barr virus infection are common features of myasthenia gravis thymus: possible roles in pathogenesis.

Cite this article as: Minervini F, Kocher GJ. When to suspect a thymoma: clinical point of view. J Thorac Dis 2020;12(12):76137618. doi: 10.21037/jtd-2019-thym-05
Autoimmune Dis 2011;2011:213092.

16. Jaretzki A 3rd, Barohn RJ, Ernstoff RM, et al. Myasthenia gravis: recommendations for clinical research standards. Task Force of the Medical Scientific Advisory Board of the Myasthenia Gravis Foundation of America. Neurology 2000;55:16-23.

17. Lippner EA, Lewis DB, Robinson WH, et al. Paraneoplastic and Therapy-Related Immune Complications in Thymic Malignancies. Curr Treat Options Oncol 2019;20:62.

18. Masaoka A, Hashimoto T, Shibata K, et al. Thymomas associated with pure red cell aplasia. Histologic and followup studies. Cancer 1989;64:1872.

19. Jansen A, van Deuren M, Miller J, et al. Prognosis of Good syndrome: mortality and morbidity of thymoma associated immunodeficiency in perspective. Clin Immunol 2016;171:12-7.

20. Hung CT, Tsai TF, Chen JS, et al. Thymomaassociated multiorgan autoimmunity. BMJ Case Rep 2019;12:e229163.

21. Wadhera A, Maverakis E, Mitsiades N, et al. Thymomaassociated multiorgan autoimmunity: a graft-versus-hostlike disease. J Am Acad Dermatol 2007;57:683-9. 